\title{
Note
}

\section{Molecular mapping of the short awn 2 (lks2) and dense spike 1 (dsp1) genes on barley chromosome $7 \mathbf{H}$}

\author{
Shin Taketa*1), Takahisa Yuo'), Yukie Sakurai'), Shoko Miyake ${ }^{2)}$ and Masahiko Ichii') \\ 1) Institute of Plant Science and Resources, Okayama University, 2-20-1 Chuo, Kurashiki, Okayama 710-0046, Japan \\ 2) Faculty of Agriculture, Kagawa University, 2393 Ikenobe, Miki, Kagawa 761-0795, Japan \\ 3) Kagawa University, 1-1 Saiwai, Takamatsu, Kagawa 760-8521, Japan
}

The short awn $2(l k s 2)$ and dense spike $1(d s p 1)$ genes are unique to East Asian barley. These two spikerelated morphological genes are important because they may be involved in stable production and local adaptation. As a first step of their positional cloning, molecular mapping was conducted in $98 \mathrm{~F}_{2}$ plants derived from a cross between Karafuto Zairai and Aizu Hadaka 3. The $d s p 1$ gene was mapped to the proximal region of the short arm of chromosome $7 \mathrm{H}$. The $l k s 2$ gene was located on the long arm of $7 \mathrm{H}$ and flanked by ESTbased markers $\mathrm{k} 04151$ and $\mathrm{k} 06123$, with distances of $0.5 \mathrm{cM}$ in the proximal side and $1.0 \mathrm{cM}$ in the distal side. Both $\mathrm{k} 04151$ and $\mathrm{k} 06123$ shared homology to rice genes on chromosome 6 that were separated with the physical distance of $5.6 \mathrm{Mbp}$. In this interval, rice-barley microsynteny was exploited for marker enrichment. Of 57 rice genes attempted, 15 (26.3\%) yielded polymorphic EST-based markers. Breakdown of collinearity was found in the candidate region of $l k s 2$, suggesting occurrence of structural changes in the chromosome region harboring $l k s 2$ during divergence of barley and rice from a common ancestor.

Key Words: collinearity, dense spike, Hordeum vulgare L., marker, microsynteny, rice, short awn.

\section{Introduction}

The awn of barley (Hordeum vulgare L.) is a linear extension of the distal end of the lemma. It was shown to contribute to photosynthesis (Kjack and Witter 1974). Different estimates have been made as to its contribution to the grain yield. Grundbacher (1963) estimated that the awn of wheat (Ttiticum aestivum L.) and barley contributes more than 10 percent of the total kernel dry weight. In barley, Qualset et al. (1965) confirmed the significant contribution of the awn to the yield from the field tests using backcross-derived isogenic lines differing in the length of the awn (full-, half-, quarter-awned, and awnless); they reported that the respective yields of full-awned and half-awned lines were significantly higher than those of either the quarter-awned or awnless lines. Despite the prevalence of full-awned phenotype in the barley crop, short-awned accessions are frequently found in eastern Asia (Takahashi 1987). Many genes are known to condition awn development in barley (Lundqvist and Franckowiak 2003). Among others, the short awn 2 (lks2) gene on chromosome $7 \mathrm{H}$ is a spontaneous recessive mutation that is distributed widely among East Asian barley ac-

Communicated by T. Komatsuda

Received October 8, 2010. Accepted November 10, 2010.

*Corresponding author (e-mail: staketa@rib.okayama-u.ac.jp) cessions, suggesting that it confers some agronomic advantages (Hayashi et al. 1972, Takahashi et al. 1953). It is particularly interesting that among East Asian barleys, which predominantly have six-rowed spikes, $l k s 2$ is often associated with the dense spike $1(d s p l)$ gene, which is also located on 7H (Takahashi 1987). Although many dense spike mutations of either natural or induced origin have been reported for barley, $d s p l$ is a spontaneous recessive mutation that is unique to eastern Asia (Lundqvist and Franckowiak 2003). Takahashi (1987) reported favorable effects of $d s p 1$ for high productivity by increasing the number of flowers per spike, but the gene decreases kernel weight to some degree.

We attempted molecular mapping of two morphological mutant genes that are unique to eastern Asia, $l k s 2$ and $d s p 1$, with the ultimate goal of their positional cloning, particularly of $l k s 2$. Here, we summarize our results of rough mapping of these two spike-related morphological genes on chromosome 7H. We also describe exploitation of rice (Oryza sativa L.)-barley microsynteny for marker enrichment of the region surrounding $l k s 2$.

\section{Materials and Methods}

For mapping, $98 \mathrm{~F}_{2}$ plants derived from a cross between Karafuto Zairai (OUJ301) and Aizu Hadaka 3 (OUJ323) 
were used. The mapping parents are both six-rowed old Japanese varieties. Karafuto Zairai has lax spikes, long awns and covered caryopsis, whereas Aizu Hadaka 3 carries both $d s p 1$ and $l k s 2$ along with the naked caryopsis (nudl) gene (Fig. 1). Here, nudl is used for the gene symbol for naked caryopsis according to the recommendation of Lundqvist and Falk (2005). Plants were grown in a greenhouse. For selected plants, $\mathrm{F}_{3}$ progeny tests were conducted using 16 plants per line to infer their genotypes for $d s p 1$ and $l k s 2$.

DNA was extracted according to the methods of Komatsuda et al. (1998). A total of 15 molecular markers were used for initial mapping. Those included three sequence-characterized amplified region (SCAR) markers derived from amplified fragment length polymorphisms (AFLP) (Kikuchi et al. 2003, Taketa et al. 2006), eight simple sequence repeat (SSR) markers (Li et al. 2003, Ramsay et al. 2000), a sequence-tagged site (STS) marker MWG511 (Künzel et al. 2000), and three expressed sequence tag (EST)-based markers (Sato et al. 2009). For MWG511, we originally selected a polymorphic enzyme HhaI; for ESTbased marker k04151, we designed a new primer set (Table 1) and selected a polymorphic restriction enzyme (BsiEI). Then PCR amplification was performed in volumes of $10 \mu \mathrm{l}$, each containing $0.5 \mathrm{U}$ of Ampli-Taq Gold DNA polymerase (Applied Biosystems, Foster City, CA, USA), $0.2 \mu \mathrm{M}$ primers, $200 \mu \mathrm{M}$ of dNTP, $1.5,2$, or $2.5 \mathrm{mM}$ of $\mathrm{MgCl}_{2}, 20 \mathrm{ng}$ of DNA and reaction buffer. Subsequently, PCR was performed with the following cycling parameters: $9 \mathrm{~min}$ at $95^{\circ} \mathrm{C} ; 30$ cycles of $1 \mathrm{~min}$ at $95^{\circ} \mathrm{C}, 1 \mathrm{~min}$ at annealing temperature of respective primers, $2 \mathrm{~min}$ at $72^{\circ} \mathrm{C} ; 5 \mathrm{~min}$ at $72^{\circ} \mathrm{C}$; with a final hold at $15^{\circ} \mathrm{C}$. Restriction enzyme treatment of PCR products and electrophoresis were done according to the procedure described by Taketa et al. (2004, 2006). Recombination values were calculated using software (Mapmaker Macintosh Version 2.0; Lander et al. 1987); a genetic linkage map was constructed based on LOD scores greater than 3.0. Map distances were calculated using the Kosambi function (Kosambi 1944).

Based on rice-barley microsynteny, we originally developed 15 EST-based markers, which have a prefix OIS followed by numerals. For development of these markers, the rice annotation project database (RAP-DB, http://rapdb.dna. affrc.go.jp/) and TIGR rice genome annotation (http://rice. plantbiology.msu.edu/) database were used. Rice gene sequences on selected rice BAC/PAC clones were used as a query for the homology search in the DDBJ database (http://www.ddbj.nig.ac.jp/Welcome-j.html). Barley ESTs giving the best match to rice orthologues were selected for primer design. Then PCR primers of around $20 \mathrm{nt}$ length were designed using Primer 3 (http://frodo.wi.mit.edu/ primer3/) and were synthesized commercially. Amplified PCR products from both parental accessions were sequenced according to Taketa et al. (2004, 2006), and polymorphic markers were developed. For chromosome arm assignment of barley markers, wheat-barley chromosome addition lines (Islam 1983, Islam et al. 1981) were used as described by

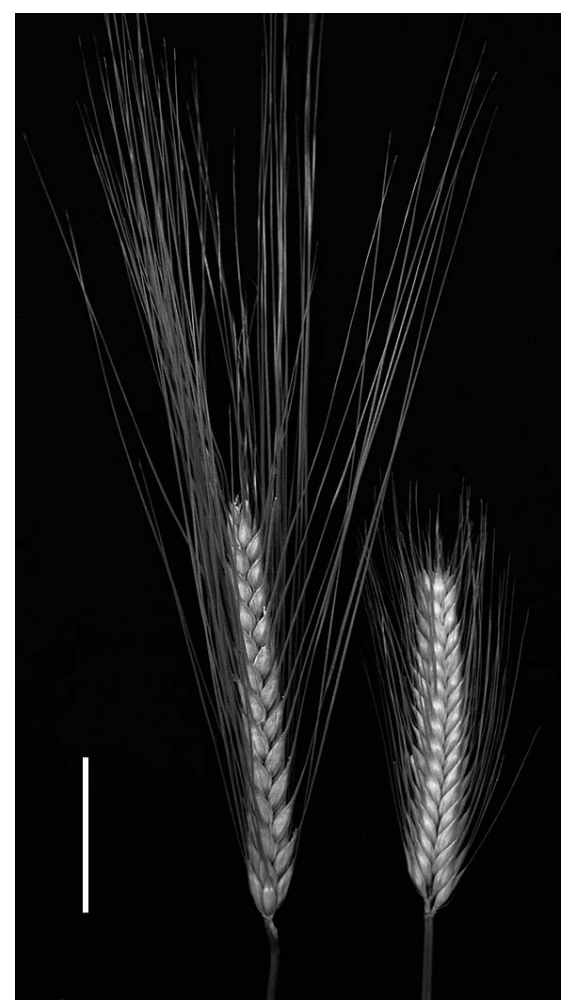

Fig. 1. Spike morphology of full-awned variety Karafuto Zairai with normal spike density (left), and short-awned (lks2) variety Aizu Hadaka 3 with dense spike ( $d s p 1)$, (right); side views are shown. Both varieties are six-rowed. $\mathrm{Bar}=5 \mathrm{~cm}$.

Taketa et al. (2010). Primer sequences, annealing temperature, amplicon size, and polymorphic restriction enzymes are summarized in Table 1.

\section{Results}

Although dspl is known to slightly reduce awn length (Sameri et al. 2006), segregation of $l k s 2$ in the mapping population was easily scored as either long or short by visual examination at maturity because $l k s 2$ homozygous plants had shorter and thinner awns. Similarly, spike density in the mapping population was easily scored as either lax (normal) or dense. No segregation distortion was found for the phenotypic traits or molecular markers examined. Using public markers, the $l k s 2$ gene was mapped on 7HL between ESTbased markers $\mathrm{k} 04151$ and $\mathrm{k} 06123$ with the respective distance of $0.5 \mathrm{cM}$ in the proximal side and $1.0 \mathrm{cM}$ in the distal side (Fig. 2). Bmac0064 cosegregated with k06123, but the distal flanking marker of $l k s 2$ was represented by k06123 because it was impossible to infer rice genes orthologous to this barley SSR marker. The $d s p 1$ gene cosegregated with three SSR markers (Bmag0359, BGMS0164, and Bmag0321) in the proximal regions of the short arm of $7 \mathrm{H}$. In the middle of the $d s p 1-l k s 2$ interval, nudl was located $8.9 \mathrm{cM}$ from $d s p 1$ and $8.2 \mathrm{cM}$ from $l k s 2$. Takahashi et al. (1953) reported that the three genes were located on $7 \mathrm{H}$ in 


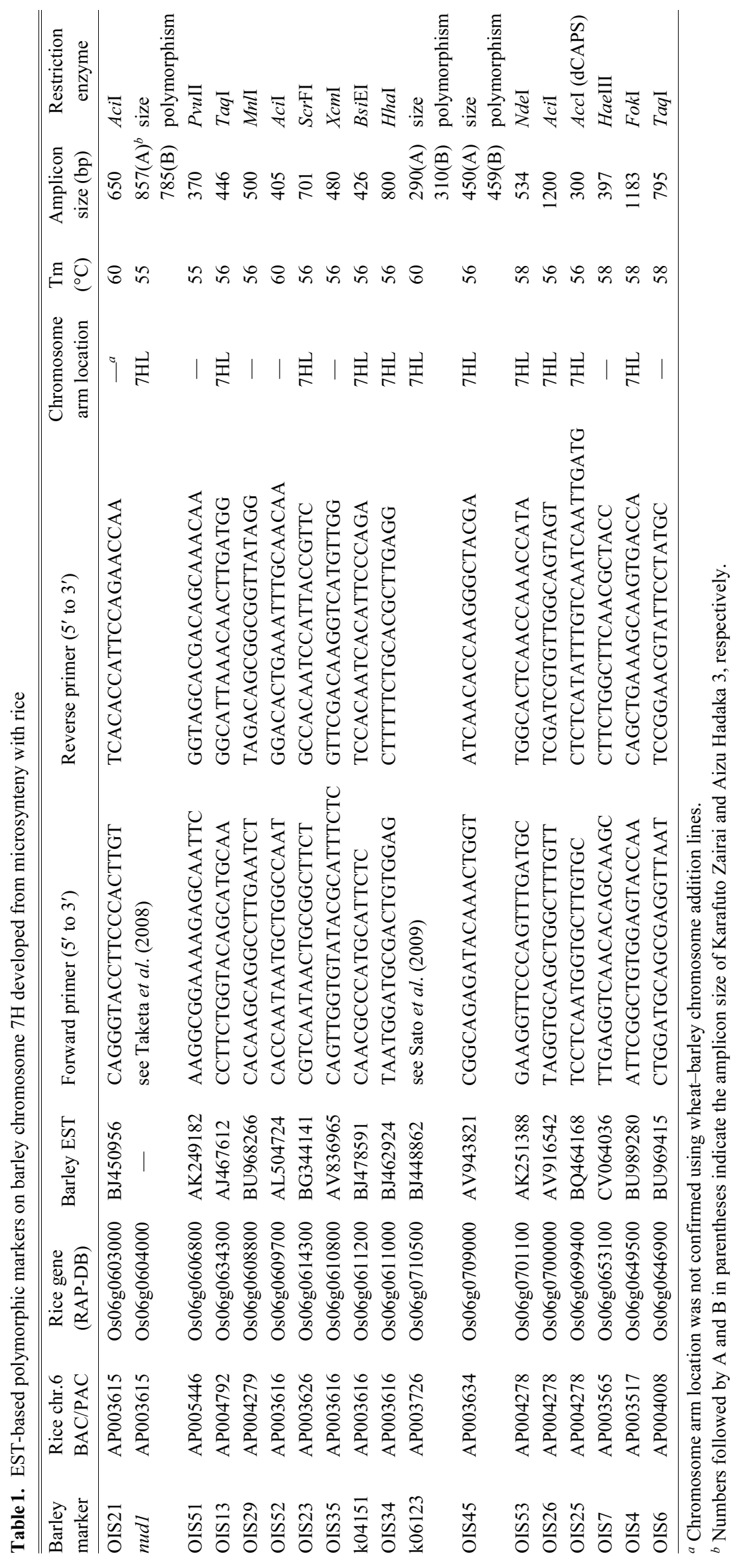


the order of $d s p 1-n u d 1-l k s 2$, and that the distances in the former and latter intervals are, respectively, 9.38\% and $8.75 \%$. The genetic distances by Takahashi et al. (1953) are based on observation of more than 2000 segregating plants of either $\mathrm{F}_{2}$ or $\mathrm{BC}_{1} \mathrm{~F}_{1}$ generations. Costa et al. (2001), based on 94 doubled haploid lines, reported that nudl and $l k s 2$ are $12.1 \mathrm{cM}$ apart on chromosome $7 \mathrm{H}$. Consequently, the relative order and genetic distances of the three morphological genes in the present study based on $98 \mathrm{~F}_{2}$ plants show good agreement with those of Takahashi et al. (1953) and Costa et al. (2001).

To enrich molecular markers near the k04151-k06123 interval, rice-barley microsynteny was exploited. A database search showed that two flanking markers for $l k s 2$, k04151 and $\mathrm{k} 06123$, share homology to rice genes Os06g0611200 and Os06g0710500 (respective e-values $2.0 \mathrm{e}^{-93}$ and $1.8 \mathrm{e}^{-06}$ ). On the physical map of rice chromosome 6 , these two genes were separated by about $5.6 \mathrm{Mbp}$. Consequently, first, four rice BAC clones (AP004008, AP003517, AP005453 and AP003565) that were located around the mid-point of this interval were chosen. Two randomly selected genes per BAC clone (a total of eight genes) were used as queries for search for homologous barley EST. Based on selected barley ESTs, primers were designed and sequences were compared between the mapping parents. In this way, three EST markers were developed: OIS4, OIS6, and OIS7 (Table 1). Unexpectedly, these markers were mapped on 7HL far distal to $l k s 2$ (Fig. 2), suggesting disturbed microcollinearity between the barley chromosome region surrounding $l k s 2$ and the corresponding rice chromosome 6 region. Similar attempts were continued, with specific attention to the rice chromosome regions that are close, respectively, to Os06g0611200 and Os06g0710500, because highly disrupted rice-barley collinearity was expected in the middle of the interval. From 49 attempts, 12 polymorphic markers were developed. Consequently, in all, 57 rice genes were attempted for rice-barley microsynteny-based marker development, and 17 out of 32 successfuly sequenced for the barley parents were monomorphic, and 15 polymorphic EST markers (suffixed by OIS) were developed with the success rate of $26.3 \%$. Then OIS35 and OIS34 occupied the same position as $\mathrm{k} 04151$, and OIS45 colocalized to k06123. However, no EST marker closer than the starting flanking EST markers was developed. In the current map (Fig. 2), all EST-based markers except for one share homology to rice genes on chromosome 6. A public marker, k07588 (Sato et al. 2009), which is $4.1 \mathrm{cM}$ distal to $l k s 2$, shares homology to a rice gene on chromosome 8 .

As the comparison between the barley genetic map and the rice physical map (Fig. 2) shows, breakdown of collinearity was observed in the region surrounding $l k s 2$; a large reversal of marker order was found between rice and barley in the region distal to $l k s 2$, suggesting an inversion in the orthologous region of barley (k06123-OIS6 interval) relative to the corresponding part of rice chromosome 6 . In contrast, in the region surrounding the nudl gene, micro-

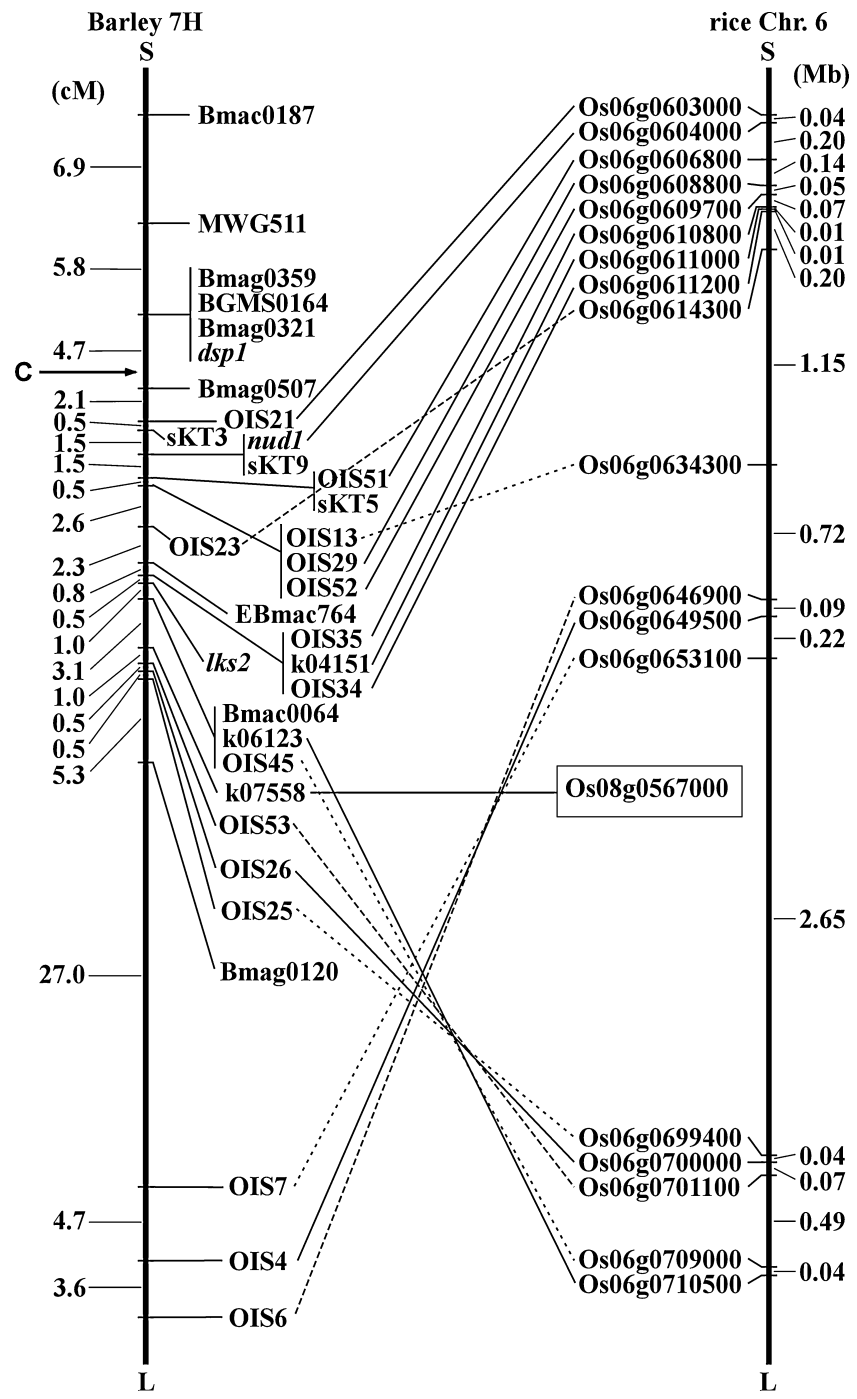

Fig. 2. Genetic map of barley chromosome $7 \mathrm{H}$, in relation to a part of the rice chromosome 6 physical map. Lines connect barley EST markers with rice orthologues. $\mathrm{C}$ in the barley genetic map shows the location of the centromere.

collinearity is highly conserved, with the exceptions of OIS23 and OIS13.

\section{Discussion}

The $d s p 1$ gene cosegregated with three SSR markers that were located in the proximal region of the short arm of $7 \mathrm{H}$. These SSR markers are assigned to 7HS using wheat-barley ditelosomic chromosome addition lines. However, it is uncertain whether $d s p 1$ is located on the proximal region of either the short arm or the long arm of $7 \mathrm{H}$ because $d s p 1$ maps close to the centromere. Sameri et al. (2006) mapped a QTL for spike density in the proximal region of the short arm of $7 \mathrm{H}$, which is very close to the $c M W G 704$ molecular marker. Although the present map does not include this marker because of the unavailability of polymorphism, $d s p 1$ seems to occupy a similar location to the dense spike QTL on the 7HS 
reported by Sameri et al. (2006). In a similar location, Shahinnia et al. (2010) reported the dense spike gene (dsp.ar) that was harbored in an X-ray induced mutant 7114. Although allelism of this dense spike gene with $d s p 1$ has not been tested yet, Shahinnia et al. (2010) claim that they occupy the identical locus. It is apparent that $d s p 1$ lies close to the centromere of $7 \mathrm{H}$ and that it is probably in the region of suppressed recombination according to the cytologically integrated molecular map of barley chromosome $7 \mathrm{H}$ (Künzel et al. 2000). Therefore, the $d s p 1$ gene appears to be only slightly accessible by map-based cloning approaches.

In this study, $l \mathrm{ks} 2$ mapped $8.2 \mathrm{cM}$ distal to $n u d 1$. Recently, the nudl gene for naked caryopsis was isolated by our group through positional cloning (Taketa et al. 2008). Considering its more distal location than that of nudl (Fig. 2), positional cloning of $l k s 2$ is expected to be feasible because of a favorable ratio of genetic/physical distance in the distal region of chromosome $7 \mathrm{H}$ (Künzel et al. 2000). The results reported herein showed that the $l k s 2$ candidate region most likely corresponds to rice chromosome 6 (Fig. 2), but the breakdown of collinearity precluded accurate determination of the $l k s 2$ candidate region on rice chromosome 6 based on rice-barley microsynteny. Structural changes are likely to include inversions and translocations occurring in the chromosome region harboring $l k s 2$ during divergence of barley and rice from a common ancestor. Therefore, as Poukheirandish et al. (2007) reported, in the case of breakdown of collinearity, construction of a BAC contig-based physical map is necessary to identify a candidate gene(s) in the target species. High-resolution genetic mapping and physical mapping of the $l k s 2$ gene is under way toward its positional cloning and functional analysis. We initiated chromosome walking from the closest flanking markers using the BAC library of a Japanese barley cultivar 'Haruna Nijo' (Saisho et al. 2007).

In wild barley, the awn facilitates seed dispersal and burial, so the long awn is considered adaptive (Harlan 1968). However, in domesticated barley, long awns may have some adverse effects. For example, under humid conditions, the awned varieties might be more susceptible to lodging than the short awned ones because the awned spikes accumulate excessive amounts of moisture during rain (Grundbacher 1963). Such lodging resistance might confer adaptive advantages to short awned varieties in eastern Asia, where precipitation is rather high because of monsoon climate zones. Molecular cloning of genes controlling the awn length might enable optimization of the barley awn length through genetic manipulation.

\section{Acknowledgments}

The authors are grateful to Dr. K. Sato for providing EST marker information before publication. Seeds of barley parental lines were provided by the National Bioresource Project - Barley, Japan. This work was partly supported by a grant from the Ministry of Agriculture, Forestry, and Fisheries of Japan (Genomics for Agricultural Innovation Grant TRC1007).

\section{Literature Cited}

Costa,J.M., A.Corey, P.M.Hayes, C.Jobet, A.Kleinhofs, A.KopischObusch, S.F.Kramer, D.Kudrna, M.Li, O.Riera-Lizarazu et al. (2001) Molecular mapping of the Oregon Wolfe Barleys: a phenotypically polymorphic doubled-haploid population. Theor. Appl. Genet. 103: 415-424.

Grundbacher,F.J. (1963) The physiological function of the cereal awn. Bot. Rev. 29: 366-381.

Harlan,J.R. (1968) On the origin of barley. In: Barley: Origin, Botany, Culture, Winterhardiness, Genetics, Utilization, Pests. Agriculture Handbook No. 338 (U.S. Department of Agriculture, Washington, DC), pp. 9-31.

Hayashi,J., I.Moriya and R.Takahashi (1972) Effects of the gene $l k s 2$ for short awn on some agronomic characters in barley. Jpn. J. Breed. 22: (Suppl. 2) 100-101.

Islam,A.K.M.R. (1983) Ditelosomic additions of barley chromosomes to wheat. In: Sakamoto,S. (ed.) Proc. 6th Int. Wheat Genet. Symp., Maruzen, Kyoto, pp. 233-238.

Islam,A.K.M.R., K.W.Shepherd and D.H.B.Sparrow (1981) Isolation and characterization of euplasmic wheat-barley chromosome addition lines. Heredity 46: 161-174.

Kikuchi,S., S.Taketa, M.Ichii and S.Kawasaki (2003) Efficient fine mapping of the naked caryopsis gene (nud) by HEGS (highefficiency genome scanning)/AFLP in barley. Theor. Appl. Genet. 108: 73-78.

Kjack,J.L. and R.S.Witters (1974) Physiological activity of awns in isolines of Atlas barley. Crop Sci. 14: 243-248.

Komatsuda,T., I.Nakamura, F.Takaiwa and S.Oka (1998) Development of STS markers closely linked to the vrs 1 locus in barley, Hordeum vulgare. Genome 41: 680-685.

Kosambi,D.D. (1944) The estimation of map distance from recombination values. Ann. Eugen. 12: 172-175.

Künzel,G., L.Korzun and A.Meister (2000) Cytologically integrated physical restriction fragment length polymorphism maps for the barley genome based on translocation breakpoints. Genetics 154 : 397-412.

Lander,E.S., P.Green, J.Abrahamson, A. Barlow, M.J.Daly, S.E. Lincoln and L.Newburg (1987) MAPMAKER: an interactive computer package for constructing primary genetic linkage maps of experimental and natural populations. Genomics 1: 174-181.

Li,J.Z., T.G.Sjakste, M.S.Röder and M.W.Ganal (2003) Development and genetic mapping of 127 new microsatellite markers in barley. Theor. Appl. Genet. 107: 1021-1027.

Lundqvist,U. and J.D.Franckowiak (2003) Diversity of barley mutants. In: Bothmer,R.v., T.v.Hintum, H.Knüpffer and K.Sato (eds.) Diversity in barley (Hordeum vulgare), Elsevier, Amsterdam, pp. 77-96.

Lundqvist,U. and D.Falk (2005) Report of barley genetic coordination workshop at the IX International Barley Genetics Symposium in Brno, Czech Republic, June 19, 2004. Barley Genet. Newslett. 35: $100-102$.

Pourkheirandish, M., T. Wicker, N. Stein, T. Fujimura and T. Komatsuda (2007) Analysis of the barley chromosome 2 region containing the six-rowed spike gene $v r s 1$ reveals a breakdown of rice-barley micro collinearity by a transposition. Theor. Appl. Genet. 114: 1357-1365.

Qualset,C.O., C.W.Schaller and J.C.Williams (1965) Performance of isogenic lines of barley as influenced by awn length, linkage blocks, and environment. Crop Sci. 5: 489-494.

Ramsey,L., M.Macaulay, S.degli Ivanissevich, K.MacLean, L.Cardle, 
J.Fuller, K.J.Edwards, S.Tuvesson, M.Morgante, A.Massari et al. (2000) A simple sequence repeat-based linkage map of barley. Genetics 156: 1997-2005.

Saisho,D., E.Myoraku, S.Kawasaki, K. Sato and K.Takeda (2007) Construction and characterization of a bacterial artificial chromosome (BAC) library from the Japanese malting barley 'Haruna Nijo'. Breed. Sci. 57: 29-38.

Sameri,M., K.Takeda and T.Komatsuda (2006) Quantitative trait loci controlling agronomic traits in recombinant inbred lines from a cross of Oriental- and Occidental-type barley cultivars. Breed. Sci. 56: $243-252$.

Sato,K., N.Nankaku and K.Takeda (2009) A high-density transcript linkage map of barley derived from a single population. Heredity 103: 110-117.

Shahinnia,F., A.Druka, R.Waugh, M.Morgante and N.Stein (2010) Positional cloning of the gene dense spike $(d s p l)$ on barley chromosome $7 \mathrm{H}$ by utilization of next generation grass-genomic tools. Plant and Animal Genomes XVIII Conference abstract p. 319.

Takahashi, R. (1987) Genetic features of East Asian barleys. In: Yasuda, S. and T.Konishi (eds.) Barley Genetics V,. Maruzen, Okayama, pp. 7-20.
Takahashi,R., J.Yamamoto, S. Yasuda and Y.Itano (1953) Inheritance and linkage studies in barley. Ber. Ohara Inst. Landw. Forsch. 10: 29-53.

Taketa, S., S.Kikuchi, T.Awayama, S.Yamamoto, M.Ichii and S. Kawasaki (2004) Monophyletic origin of naked barley inferred from molecular analyses of a marker closely linked to the naked caryopsis gene (nud). Theor. Appl. Genet. 108: 1236-1242.

Taketa,S., T.Awayama, S.Amano, Y.Sakurai and M.Ichii (2006) High-resolution mapping of the nud locus controlling the naked caryopsis in barley. Plant Breed. 125: 337-342.

Taketa, S., S. Amano, Y.Tsujino, T. Sato, D. Saisho, K. Kakeda, M.Nomura, T.Suzuki, T.Matsumoto, K.Sato et al. (2008) Barley grain with adhering hulls is controlled by an ERF family transcription factor gene regulating a lipid biosynthesis pathway. Proc. Natl. Acad. Sci. USA 105: 4062-4067.

Taketa,S., K.Matsuki, S.Amano, D.Saisho, E.Himi, N.Shitsukawa, T.Yuo, K. Noda and K.Takeda (2010) Duplicate polyphenol oxidase genes on barley chromosome $2 \mathrm{H}$ and their functional differentiation in the phenol reaction of spikes and grains. J. Exp. Bot. 61: 3983-3993. 